\title{
EFFECTS OF THE SIMULATION BASED TRAINING PROGRAM ON ATTITUDES OF NURSES TOWARDS OLDER ADULTS: A QUASI-EXPERIMENTAL DESIGN STUDY
}

\section{Burcu Akpinar Soylemez ${ }^{1}$, Ozlem Kucukguclu, ${ }^{1,2}$, Merve Aliye Akyol ${ }^{1,2}$, Nil Tekin $^{3}$, Ahmet Turan Isik ${ }^{4}$}

${ }^{1}$ Dokuz Eylul University Faculty of Nursing, Department of Internal Medicine Nursing, Izmir, Turkey

2 Dokuz Eylul University, Home Care Application and Research Center, Izmir, Turkey,

${ }^{3}$ Narlıdere Residential and Nursing Home, Izmir, Turkey

${ }^{4}$ Dokuz Eylül University, Faculty of Medicine, Department of Geriatrics, Izmir, Turkey

Address for Correspondence: Burcu AKPINAR SOYLEMEZ E-mail: burcu.akpinar@deu.edu.tr Received: 25.07.2021; Accepted: 04.08.2021; Available Online Date: 20.08.2021

(C) Copyright 2021 by Dokuz Eylül University, Institute of Health Sciences - Available online at https://dergipark.org.tr/en/pub/jbachs

Cite this article as: Akpinar Soylemez B, Kucukoglu O, Akyol M.A, Tekin N, Isik A.T. Effects of the Simulation Based Training Program on Attitudes of Nurses Towards Older Adults: A Quasi-Experimental Design Study J Basic Clin Health Sci 2021; 3: 186- 194.

\begin{abstract}
Purpose: Innovative activities such as the simulation-based training program can affect nurses' attitudes toward older adults. This study was aimed to determine the effects of the simulation-based training programs on nurses' attitudes towards older adults in institutional care settings.

Methods: A quasi-experimental pretest-posttest design was used. A total of 92 nurses participated in simulation-based training program that comprised presentation about care for older adults, and scenario with aged simulation suit. Data were collected using a Participant Information Form and Kogan's Attitudes Toward Old People Scale. The value, mean, percentage frequency distribution, and paired sample t-test were used.

Results: After the simulation-based training programs were completed, the mean total score $(p=0.001)$ and positive attitudes of score of the nurses was changed statistically significantly $(p=0.001)$. There was no statistically significant change negative attitudes $(p=0.274)$.

Conclusions: The simulation-based training program is effective in developing more positive and less negative attitude toward the older adults by nurses in institutional care settings. The aging-simulation experience affected health professionals' feelings and knowledge. To provide better care for the older adults, it is important that nurses adopt a positive attitude toward the older adults.
\end{abstract}

Keywords: Aged, Attitude, Nurses, Nursing Homes.

\section{INTRODUCTION}

The number of older adults receiving institutional care service is gradually increasing (1). Their possibility of receiving quality care is closely related to the attitudes of nurses who provide care (2). Previous studies on 
determining the attitude of healthcare professionals toward the older adults date back to almost half a century ago. Presently, there are studies examining attitudes toward the older adults as well as systematic reviews examining these studies. In a systematic review conducted by Liu et al. (2013) to examine the attitude of working and studying nurses toward the older adults, 25 studies were examined, and only two of these studies are interventional studies (3). Many studies on this subject have been conducted to determine the current attitude of nurses crosssectionally (3-5). Studies aiming to improve the attitude of nurses toward the older adults are limited (5-9). In Turkey, no study could be found that aimed to improve the positive attitudes of nurses toward the older adults. In literature, geriatric training programs are needed that aim to reduce the negative attitude of the nurses working in nursing homes toward the older adults, improve their positive attitudes, and develop new approaches like simulation based interventions. Interventions aimed at improving the attitude of working nurses toward the older adults should be multi-dimensional. Furthermore, consultations and trainings within the framework of evidence-based geriatric protocols should be provided by nurses specialized in their respective fields (5). Interactive approaches should be included in the content of educational initiatives and motivation of healthcare professionals should be increased with constructive feedbacks (10). In a systematic review, Ross et al. (2015) examined the effectiveness of educational initiatives in improving the attitudes of healthcare students toward the older adults; they stated that educational initiatives are in the form of conventional education approach, workshops, simulations and dramatizations, or a combination of these (7). Demirtas \& Basak (2020) has been noted that simulation of daily life activities is effective in improving nursing students' positive attitudes toward older adults (11). Sari et al. (2020) stated that an aged simulation suit has proven to be an effective intervention. In additon to this they stated that participant feedback showed that the this intervention increased empathy and awareness about geriatric nursing (12). In a recent systematic review, EostTelling et al., (2021) stated that aged simulation equipments/suits can have a positive effects on students' attitudes and empathy towards older adults (13).

Rueffort and Bullinger (2020) examined whether wearing an age simulation suit would make a sensitization compared to participants observing the intervention. A high sensitivity for age-related impairments was observed in both the groups. They stated that observing age simulation intervention could also be a good way for effective training (8). Perot et al. 2020 investigated the impacts of an agingsimulation experience on health professionals' understanding of age-related limitations. They stated that this experience is an effective method for increasing the awareness of health professionals about age-related difficulties. It also stated that this experience allowed them to put themselves in the shoes of older adults and to experience age-related difficulties (6).

The recent studies have been made to change nursing students' attitudes towards the elderly (1113). But the studies on changing the attitudes of nurses who work actively with the elderly (geriatric care nurses) towards the elderly are limited. Therefore, in the current study, the aim was to determine the effects of the simulation-based training programs on nurses' attitudes towards older adults in institutional care settings.

Hypotheses of the study were as follows:

$\mathrm{H} 1$ : The simulation based training program applied to nurses have an effect on the attitudes of nurses towards older adults.

$\mathrm{HO}$ : The simulation based training program applied to nurses do not have any effect on the attitudes of nurses towards older adults.

\section{METHODS \\ Design}

A quasi-experimental pretest-posttest design was used between February and March 2019 (see Fig. 1). The hypothesis "Nurses positive attitude toward elderly scores are higher after simulation-based training program compared to the pre-test" and "Nurses negative attitude toward elderly scores are lower after simulation-based training program compared to the pre-test" were tested in this study.

\section{Participants and setting}

One hundred and five nurses employed at the Nursing Home Elderly Care and Rehabilitation Center affiliated with the Provincial Directorate of Family, Labor, and Social Services of Izmir. Program was announced. There was only one inclusion criteria of the study was to be volunteer. A total of 93 nurses participated in the study voluntary. Participant Information Form and Kogan's Attitudes Toward Old 
People Scale were applied. Considering gender, age and scale score diversity from different nursing homes, five groups were formed. Group participant ranged from 18 and 20. Simulation-based training program was applied to each group. First and second day plan of each group were shown in Fig. 1. One nurse in third group was drop out because not attend the 2nd day of the program. Finally, 92 nurses completed the study. The power of study (0.99) and effect size (0.5) with an alpha value of 0.05 were evaluated using G-power. The power analysis was indicated posthoc analysis.

\section{Total of 105 Nursing Home Nurses}

Affiliated with the Provincial Directorate of Family, Labor, and Social Services of İzmir.

$\checkmark$ Program was announced.

$\checkmark$ Participant Information Form (pretest)

$\checkmark \quad 93$ Volunteer Nursing Home Nurses

$\checkmark$ Kogan's Attitudes Toward Old People Scale (pretest)

Considering gender, age and scale score diversity from different nursing homes, five groups were formed.

Group participant range (18-20)

Simulation-based training program was applied to each group $(n=93)$.

First day of each group:

$>$ Opening ceremony

$>$ Briefly describe simulation-based training program

$>$ Given education about geriatric care (8 hours)

(Topics: aging in a changing society, age-related physiological changes, psychosocial aspects of aging, geriatric syndromes)

Setting the tomorrow activities of the program

\section{Second day of each group:}

$>$ Summary of the previous day

$>$ Every participant completed scenario with aged simulation suit (for an average of 30-40 minutes) (see Table 1)

$>$ Experiences sharing session was held about the simulation

$>$ Feedback and discussion session was held about the program

$>$ Kogan's Attitudes Toward Old People Scale (posttest) $(\mathbf{n}=92)$

drop out $(\mathbf{n}=\mathbf{1}) *$ did not attend the $2^{\text {nd }}$ day of the program

Figure 1. Flow Diagram (TREND Statement) 
Table 1. Example of scenario

\begin{tabular}{lll}
\hline Station & Simulation feature & Activities \\
\hline Taking Pills & Tinnitus headphones Neck brace & \\
& $\begin{array}{l}\text { Tremor simulation } \\
\text { A pair of goggles to simulate vision impairment (in } \\
\text { case of cataract, glaucoma, diabetic retinopathy, } \\
\text { retinitis pigmentosa, unilateral retinal detachment, } \\
\text { and macular degeneration) }\end{array}$ & $\begin{array}{l}\text { Nurses were asked to find right pills and read } \\
\text { medine prescribing information and taking } \\
\text { medine with a glass of water. }\end{array}$ \\
& Gloves for palm & $\begin{array}{l}\text { education while wearing an ear plug. After the } \\
\text { education, nurses were asked to explain the } \\
\text { education. }\end{array}$ \\
& &
\end{tabular}

\section{Simulation-Based Training Program}

The simulation-based training program that comprised presentation about care for older adults, and scenario with aged simulation suit. First day of the program, nurses had an education about geriatric care. Education topics contained issues such as aging in a changing society, age-related physiological

changes, psychosocial aspects of aging, geriatric syndromes and problems (Alzheimer's disease, incontinence, physical restraint, hydration, nutrition, pressure wound, and enteral nutrition), and perception of the older adults in society.

Second day of the program, the Aged Simulation Suit (GERT) was used to understand/recognize agerelated limitations and to approach them empathically (14). The suit comprised a set of hearing lossinducing and tinnitus headphones, neck brace, a pair of goggles to simulate vision impairment (in case of cataract, glaucoma, diabetic retinopathy, retinitis pigmentosa, unilateral retinal detachment, and macular degeneration), tremor simulator, knee wraps to restrict the mobility of the knees, simulation of back pain, and overshoes at the feet to evoke feelings of nerve loss at the extremities. The simulation was designed to understand that how to affected older adults with sensory loses with aging. Each nurse was asked to do some of the activities in the stations for, mobility, dressing, eating, drinking, reading, brushing hair, taking their pills in line with the scenario prepared. The suitabbility of the scenario was evaluated by two academicians, one nurse experiences in geriatric nursing and one geriatrician (Table 1). After the simulation-based training program, the participants shared their experiences during the simulation and the effects of this experiences on them.

\section{Instruments}

Participant Information Form: This form obtains data on variables that may affect nurses' sociodemographic information and attitudes towards older adults (i.e., age, gender, the school he/she graduated from, how many years he/she has worked as a nurse, how many years he/she has worked in that institution, whether he/she had lived with an older adults before, whether he/she had any previous experience with older adults care, whether he/she received a special education for the older adults and their care before starting employment, whether he/she has a certificate in geriatrics, whether he/she started to work in the field of geriatrics voluntarily, whether he/she would like to work with the older adults again if he/she had another chance to choose an area of employment, and health status of older adults he/she has cared for).

\section{Kogan's Attitudes Toward Old People Scale:} Kogan's Attitudes Toward Old People Scale was developed by Kogan (1961) to evaluate attitudes toward the older adults (15). In a systematic review, eight different scales used in 42 different studies published to examine nursing students' attitudes towards older adults were examined, and the Kogan's scale was defined as the most reliable and most frequently used scale to measure attitudes towards older adults (16). The scale, which includes 17 positively and 17 negatively items about the older adults, is a six-point Likert type. The negative items are reverse-scored. A minimum of 34 and a maximum of 238 scores are obtained from the Kogan's scale. Higher scores indicate a positive attitude toward the older adults, whereas lower scores indicate the opposite. The psychometric properties of Turkish version of Kogan's were examined by Küçükgüçlü, et 
al., 2011 and cronbach's alpha reliability coefficient was 0.89 (17).

\section{Procedures}

Data were collected between February (2 group completed) and March (3 group completed) 2019. Firstly meetings were made with Provincial Directorate of Family, Labor and Social Services to take support to announced the project to nurses. After the announcement, volunteer nurses were determined. Participant Information Form and Kogan's Attitudes Toward Old People Scale were applied as a pretest. Considering gender, age and scale score diversity from different nursing homes, five groups were formed. Number of participants in each group not exceeding 20 . The simulation-based training program was applied to each group. First and second day plan of each group were shown in Fig. 1. After the program Kogan's Attitudes Toward Old People Scale were applied as a posttest.

Training program (2 days for each nurse) were designated as working hours for the nurses to participate in cooperation with the Provincial Directorate of Family, Labor, and Social Services. The training was delivered by three of researchers. After the topics in the training program had been conveyed, each participant experienced the Age Simulation Suit (GERT) for an average of $30-40$

Table 2. Sociodemographic characteristics of the participants $(n=92)$

\begin{tabular}{lll}
\hline & Mean & SD \\
\hline Age & 35.67 & 8.37 \\
Years worked as a nurse & 13.82 & 7.09 \\
Years worked at the institution & 8.59 & 4.92 \\
& N & $\%$ \\
Gender & 78 & 84.8 \\
Female & 14 & 15.2 \\
Male & & \\
Graduated school & 44 & 47.8 \\
Vocational School & 42 & 45.7 \\
University & 6 & 6.5 \\
Postgraduate Education & & 17.4 \\
Previously taken any course regarding the older adults & 16 & 82.6 \\
Yes & 76 & \\
No & & 59.8 \\
Had previous experience of living with an older adults & 55 & 40.2 \\
Yes & 37 & \\
No & & \\
Experience providing care to an older adults before starting to & & \\
work & & 47.8 \\
Yes & 44 & 52.2 \\
No & 48 & \\
Received training before starting to work & & 5.4 \\
Yes & 5 & 94.6 \\
No & 87 & \\
Started to work with the older adults voluntarily & & \\
Yes & 74 & \\
No & 18 & \\
Wished to continue working with older adults if they had a & & \\
choice & & \\
Yes & 75 & \\
No & & \\
& & \\
\hline
\end{tabular}


Table 3. Comparison of dependent variables at baseline and posttest $(n=92)$

\begin{tabular}{lllll}
\hline & Pretest & Posttest & \\
& Mean (SD) & Mean (SD) & $\mathrm{t}$ test & $\mathrm{p}$ \\
\hline $\begin{array}{l}\text { Positive attitudes } \\
\text { scores }\end{array}$ & $72.34(13.52)$ & $78.46(12.75)$ & -5.242 & $0.001^{\mathrm{a}}$ \\
$\begin{array}{l}\text { Negative attitudes } \\
\text { scores }\end{array}$ & $62.54(11.98)$ & $61.27(12.84)$ & 1.100 & 0.274 \\
Total attitudes scores & $145.80(19.64)$ & $153.19(20.11)$ & -4.288 & $0.001^{\mathrm{a}}$
\end{tabular}

t value: independent sample $t$ test $a, p<0.05$

minutes for each scenario. Under the guidance of the researchers, nurses were taken to each station in groups of two and three. The experience of the nurses was not interfered with except in dangerous situations to provide a real experience. Thereafter, discussion sessions were held, and discussion environments were created wherein the nurses could integrate the skills learned with clinical practices.

\section{Data analysis}

Data analyses were performed using the SPSS 22.0 software. The value, mean, and percentage frequency distribution were used. Pre and posttest changes were assessed using paired t-test because the data were normally distributed. The results were evaluated using 95\% confidence interval, and a $p$ value of $<0.05$ was considered statistically significant.

\section{Ethical considerations}

Ethical approval for the study was obtained from the Ethical Committee of Dokuz Eylul University (2016/33-04), and

written permission was received from the Izmir Provincial Directorate of Family, Labor, and Social Services. Individuals were informed about the aim and design of the study and their oral and written consents were obtained.

\section{RESULTS}

\section{Demographic characteristics and experiences}

Mean age of the participants was $35.67(\mathrm{SD}=8.37$ ) and $84.8 \%$ were females. Furthermore, $82.6 \%$ nurses had not previously taken any course regarding the older adults, $94.6 \%$ had not received training before starting to work, $59.8 \%$ had previous experience of living with an older adults, $47.8 \%$ had experience providing care to an older adults before starting to work, $80.4 \%$ started to work with the older adults voluntarily, and $81.5 \%$ wished to continue working with older adults, if they had a choice (Table 2).

\section{Nurses' attitudes toward older adults}

The mean total score of Kogan's score of the nurses was 145.80 (SD = 19.64), the score for positive attitudes 72.34 (SD = 13.52), and the score for negative attitudes $62.54(S D=11.98)$ at baseline. After intervention, the mean total score of Kogan's score of the nurses was 153.19 (SD $=20.11, t=$ $-4.288, p<0.001)$, the score for positive attitudes $78.46(S D=12.75, t=-5.242, p<0.001)$, and the score for negative attitudes $61.27(S D=12.84, t=$ $1.100, p=0.247$; Table 3).

\section{DISCUSSION}

In this study, it was investigated the effect of an simulation-based training program on nurses' attitudes toward the older adults. The simulationbased training program increased the positive attitude and decreased the negative attitudes of nurses toward the older adults. Previous studies have shown that simulation-based intervention is effective; the results of this study were similar to those of the other studies $(6,8)$. The aging-simulation experience affected health professionals' feelings and knowledge (6). To provide better care for the older adults, it is important that nurses adopt a positive attitude toward the older adults and develop an interest for geriatric nursing. Almost all the nurses $(94.6 \%)$ reported that they did not receive training for the older adults before starting to work with the older adults and $82.6 \%$ reported that they did not take any course regarding the older adults during their educational period. Previous studies have shown that attitude toward the older adults is affected by education (18-20). It is recommended to develop nationally accredited and structured geriatric education programs. In the 
present study, nurses stated that they were positively influenced by their simulation-suit experiences. Therefore, the content of such an education program should be enriched with practical courses and simulations. The simulation-based interventions should be adopted in such education programs. Respect for the older adults, mostly developed within the family, is an important feature of Turkish culture. In the present study, $>50 \%$ nurses (59.8\%) had previous experience of living with an older adult. Therefore, the higher positive attitude of nurses at baseline is thought to have arisen from the previous experiences of living with an older adult. Social norms play important roles in shaping attitudes. But social structure is changing nowadays. There is a faster transition to nuclear family structure. Since individuals who will become nurses in the future will not gain experience by living with an older adult, education studies will more importance in a positive way. Attitude is affected to a great extent by social processes, and it is shaped by sociocultural, political, and economic factors as well as by value and belief systems (21). Therefore, it is important to know what attitude is displayed toward the older adults in social and cultural terms. The older adults might be perceived by many people as a population with mental and physical disabilities that impose an economic burden on the society. Attitudes toward the older adults are transferred to people as a cultural heritage while they are still in family life before starting the nursing profession. Negative points of view pertaining to the older adults such as being unproductive, having reduced skills, becoming increasingly dependent, not being able to meet daily care needs, and not being able to walk lead to the perception of the older adults as a burden in societies (22). The willingness of healthcare professionals to work with the older adults is negatively affected if they have high negative attitudes toward the older adults, and the number of people who want to work with the older adults is decreasing despite an increasing need for the same in the healthcare sector $(21,23)$. The desire to work with the older adults is closely associated with displaying positive attitude $(3,4)$. The present study found that $80.4 \%$ nurses started to work with older adults voluntarily, and $81.5 \%$ wished to continue working with the older adults even if they had a choice. The positive attitude of nurses toward the older adults is due to this fact. It is believed that this result reflects the positive attitude toward the older adults in the Turkish society. It is thought that nurses who have a socially positive attitude toward older adults are more positively affected by this training program.

\section{CONCLUSION}

This is the first study in Turkey, to the best of our knowledge, to test the effects of the simulation-based training program for nurses providing institutional care on nurses' attitudes toward the older adults. The results of the study revealed important information that simulation-based training program can be conducted to increase positive attitudes toward the older adults. After the simulation-based training program, nurses developed a more positive and less negative attitude toward the older adults. The increase in total and positive attitude scores will increase the quality of nursing care in the older adults.

Limitations: The lack of a control group was the main limitation of this study. Nurses who participated in simulation-based training program had characteristics that did not attribute to the entire group working with the older adults, such as private nursing home or hospice nurses. Participants stated that they were especially satisfied with the simulation-based training program and their empathy toward the older adults also developed. Therefore, it is essential to test the effects of the simulation-based training program for nurses providing older adults care on nurses' attitudes and empathy toward the older adults. It is well known that attitude change is a difficult task that takes a lot of time. It is necessary to see clinical practice in attitude change. It is recommended to plan studies with longer period between the pre-test and post-test. In the future, randomized-controlled studies are needed to investigate whether these programs improve nursing care quality. Despite these limitations, we suggest the simulation-based training program for nurses who have just started to work in institutions to improve their attitudes toward the older adults.

Acknowledgements: We would like to extend our sincere thanks to the nurses who participated in the study; Nesim TANĞLAY, İzmir Provincial Director of Family, Labor, and Social Services; Institution Directors Atike ÖZTÜRK and İbrahim ARSLAN who provided the necessary environment and full support in the realization of the trainings; Research Assistants Bilgehan ÖZKAYA SAĞLAM, Baran GÜL and İzlem SÖZERI ESER for their support during the training program process; and Scientific Research Projects Coordination Unit of Dokuz Eylul University University (2018.KG.SAG.41) that provided the necessary support to conduct this study. The authors have declared that they have no conflicts of interest. Written 
informed consent was obtained from participants who participated in this study.

This study was presented as an oral presentation at the $2 \mathrm{n}^{\text {d }}$ International Internal Diseases Nursing Congress (17-19 December 2020, Izmir TURKEY).

Conflict of Interest: None.

Peer-review: Externally peer-reviewed.

\section{REFERENCES}

1. Ministry of Family and Social Policies, Directorate General of Services for Persons with Disabilities and Elderly People. Residential and Nursing Homes connected to our General Directorate (Data for September 2019) Retrieved from: https://www.ailevecalisma.gov.tr/eyhgm/kurulusl ar/yasli/ Accessed July 25, 2021.

2. Burnes D, Sheppard C, Henderson Jr C., Wassel M, Cope R, Barber C, Pillemer K. Interventions to reduce ageism against older adults: A systematic review and meta-analysis. Am J Public Health 2019;109(8), e1-e9.

3. Liu Y-E, Norman IJ, While AE. Nurses' attitudes towards older people: A systematic review. Int J Nurs Stud. 2013;50(9):1271-1282.

4. Akpinar Soylemez B, Kucukguclu O, Tekin N, Akyol MA, Isik AT. Nursing homes nurses' attitudes toward older people and affecting factors. Turk J Geriatr. 2018;21(2):271-278.

5. Tavares JPA, Silva AL, Sa-Couto P, Boltz M, Capezuti E. Portoguese nurses' knowledge of and attitudes toward hospitalized older adults. Scand J Caring Sci. 2015;29(1):51-61.

6. Perot JG, Jarzebowski W, Lafuente-Lafuente C, Crozet C, Belmin J. Aging-simulation experience: Impact on health professionals' social representations. BMC Geriatrics 2020;20(1):14.

7. Ross L, Williams $B$, Jennings $P$. The effectiveness of educational interventions designed to improve health care students behaviors and/or attitudes toward older people: A systematic review protocol. JBI Database System Rev Implement Rep. 2015;13(7):13-23.

8. Rueffert D, Bullinger AC (2019, July) Observing or Experiencing-The Effect of Age Simulation on the Sensitivity to Age-Related Impairment in Elderly Care. In: Goonetilleke R., Karwowski W. (Eds) Advances in Physical Ergonomics and Human Factors. 1st edition, Advances in Intelligent Systems and Computing (pp 339-347), Springer.

9. Wendel VI, Durso SC, Cayea D, Arbaje AI, Tanner E. Implementing staff nurse geriatric education in the acute hospital setting. MEDSURG Nursing 2010;19(5):274-280.

10. McCloskey R, Yetman L, Stewart C, Slayter J, Jarrett $P$, McCollum A, Stoica G. Changes in nursing students' knowledge, attitudes and interest in caring for older adults: A longitudinal cohort study. Nurse Educ Pract 2020;44,102760.

11. Demirtas A, Basak T. Daily activities simulation: Improving nursing students' attitudes toward older patients. Jpn J Nurs Sci. 2020:e12375.

12. Sari D, Taskiran N, Baysal E, Acar E, Cevik Akyil R. Effect of an aged simulation suit on nursing students' attitudes and empathy. Eur Geriatr Med. 2020;11(4),667-675.

13. Eost-Telling C, Kingston $P$, Taylor L, Emmerson L. Ageing simulation in health and social care education: A mixed methods systematic review. J Adv Nurs. 2021;77(1):23-46.

14. GERT Age simulation suit Retrieved from: www.age-simulation-suit.com Accessed July 25, 2021.

15. Kogan N. Attitudes toward old people: The development of a scale and an examination of correlates. J Abnorm Psychol. 1961;62(1):44.

16. Neville $C$. Undergraduate nurse attitudes toward older adults and perceptions of working with older adults: An analysis of measurement instruments. Nurse Educ Today. 2015;35(1):183-188.

17. Küçükgüçlü Ö, Mert H, Akpinar B. Reliability and validity of Turkish version of attitudes toward old people scale. J Clin Nurs. 2011;20(21-22):31963203.

18. Koh GCH, Ling CLH, Chen Cynthia C, Lim WS, Scherer SC, et al. Effect of a new longitudinal interprofessional geriatric medicine educational track on knowledge and attitude of medical students: A controlled cohort study. J Am Geriatr Soc. 2015;63(3):558-564.

19. Turan E, Yanardağ M, Metintas S. Attitudes of students of health sciences towards the older persons. Nurse Educ Today. 2016;36:53-57.

20. Tufan F, Yuruyen M, Kizilarslanoglu MC, Akpinar T, Emiksiye S, Yesil Y, et al. Geriatrics education is associated with positive attitudes toward older people in internal medicine residents: A multicenter study. Arch Gerontol Geriatr. 2015;60(2):307-310.

21. Chance K, Simpler B, Forehand JW, Spurlock A, Alberich J. An international effort examining nursing student attitudes toward older people. Teach Learn Nurs 2021;16:125-130. 
22. Bowden A, Wilson V, Traynor V, Chang HC. Exploring the use of ageing simulation to enable nurses to gain insight into what it is like to be an older person. J Clin Nurs 2020;29(23-24), 45614572.

23. Birimoglu Okuyan C Bilgili N, Mutlu A. Factors affecting nursing students' intention to work as a geriatric nurse with older adults in Turkey: A cross-sectional study. Nurse Educ Today 2020;95,104563. 